\title{
In vitro assessment of Schistosoma mansoni cercaricidal activities of Solanum nigrum and Callistemon citrinius leaves extracts and cercarial genetic changes by RAPD-PCR
}

\author{
Gehan S Sadek, Nancy M Harba, Mona F Faheem
}

Department of Medical Parasitology, Faculty of Medicine, Menoufia University, Egypt

\begin{abstract}
Background: Schistosomiasis is contracted by exposure to fresh water containing cercariae that develop into adult worms after penetration of human skin. Interruption of schistosomiasis vital cycle by elimination of cercariae may enhance methods of transmission control.

Objective: To evaluate the in vitro effect of methanol extracts of Solanum nigrum (S. nigrum) and Callistemon citrinus (C. citrinus) leaves on Schistosoma mansoni cercarial genetic makeup by random amplification of polymorphic DNA -polymerase chain reaction (RAPD-PCR).

Material and Methods: The effect of different concentrations of both plants extracts on cercarial morphology and mortality was observed with different lethal concentrations (LC). Also, assessment of DNA changes in exposed $S$. mansoni cercariae to LC50 of both plants in comparison with non-exposed ones by RAPD-PCR assay was investigated. Cercariae were divided into three groups: group A: control non-exposed cercariae; group B: cercariae exposed to $S$. nigrum; and group C: cercariae exposed to C. citrinus.

Results: The cercaricidal potency of tested extracts was concentration-dependent. The cercaricidal toxicity of $S$. nigrum extracts was 1.2 times higher than that of $C$. citrinus (LC90 values were $50 \mathrm{mg} / \mathrm{L}$ and $60 \mathrm{mg} / \mathrm{L}$, respectively). RAPD PCR revealed different band polymorphism patterns for each primer used and cercariae exposed to $S$. nigrum revealed a higher number of band polymorphism (20 bands) than that obtained by cercariae exposed to $C$. citrinus (16 bands) which were different from those of control group reflecting the genetic variability among the groups studied.

Conclusion: C. citrinus and S. nigrum are effective cercaricidal agents that can be utilized to minimize water transmission of schistosomiasis. Also, RAPD-PCR is useful for examining the genetic polymorphism of schistosomal cercariae induced by plants extracts, and assessment of genetic damage of drug development fields.
\end{abstract}

Keywords: C. citrinus, genetic polymorphism, RAPD-PCR, S. mansoni cercariae, S. nigrum.

Received: 20 January, 2019, Accepted: 17, February, 2019.

Corresponding Author: Nancy M Harba, Tel.: 00201006781775, E-mail: nancyharba@yahoo.com

Print ISSN: 1687-7942, Online ISSN: 2090-2646, Vol. 12, No. 1, April, 2019.

\section{INTRODUCTION}

Schistosomiasis, a chronic parasitic disease caused by trematodes of genus Schistosoma, is the second most devastating disease in terms of morbidity and mortality in the world. It is prevalent in tropical and subtropical areas affecting approximately 240 million people worldwide and about 700 million people are at risk, especially in poor communities lacking adequate sanitation ${ }^{[1,2]}$. Inhabitants are infected by free-swimming cercariae shed from infected snail intermediate hosts into fresh water, where they penetrate the skin during water contact and mature into adult worms ${ }^{[3]}$. Praziquantel is the main drug used for schistosomiasis control. However, there is a possibility of re-infection even after repeated chemotherapy ${ }^{[4]}$. So, complementing chemotherapy with interruption of the disease vital cycle by snails or cercariae elimination is necessary to prevent re-infection in endemic areas. Attacking schistosome cercariae in water is a new aspect for schistosomiasis transmission control ${ }^{[5]}$.

Molluscicidal plants are inexpensive, safe and appropriate for local snail control ${ }^{[6,7]}$. Consequently, more efforts focused on detecting safe molluscicides of plant origin[8], especially if they have miracidicidal and cercaricidal activities ${ }^{[9]}$. Plants from Solanaceae family with several species of Solanum plants are widely used for medicinal purposes ${ }^{[10]}$. S. nigrum was found to have potentially useful molluscicidal activity and Egyptian $S$. nigrum extracts were found to be very effective for schistosomes and Fasciola intermediate hosts control ${ }^{[11]}$. Also, Callistemon species are used as bio-indicators for environmental management ${ }^{[12]}$. It has been proved that methanol extracts of $C$. viminalis fruit, barks and leaves have molluscicidal activity against Biomphalaria alexandrina (B. alexandrina) snails ${ }^{[13]}$. $C$. citrinus is the most widely cultivated member of the genus Callistemon.

RAPD technique developed by Williams et al., ${ }^{[14]}$ was successfully used for fast and simple detection of genomic variations among parasites ${ }^{[15]}$, and the genetic polymorphisms involved in the mechanism of drug resistance ${ }^{[16,17]}$. Also, it provides a screening method to identify regions of genomic amplification, deletion, or rearrangement referred to genetic damage ${ }^{[18]}$. 
RAPD technique utilizes primers of short synthetic oligonucleotides (10 bases long) of random sequences to amplify nano-gram amounts of total genomic DNA by PCR without the need for prior sequence information about the analyzed genome, and yields information on a large number of loci throughout the genome ${ }^{[14,19]}$. Studies on genetic polymorphisms in different life cycle stages of the $S$. mansoni are few in the fields of drug development using RAPD-PCR assay ${ }^{[17]}$. In this research article, the in vitro $S$. mansoni cercaricidal activities of methanol extracts of $S$. nigrum and $C$. citrinus leaves were evaluated; and their potential anti-schistosomal effects on cercarial genetic polymorphisms were studied using RAPD technique.

\section{MATERIAL AND METHODS}

This case control analytical study was carried out during the period from February to December 2016 at the Medical Parasitology Department, Faculty of Medicine, Menoufia University, while RAPD PCR technique was processed at the Agricultural Research Institute, Giza.

Preparation of plant extracts: $S$, nigrum and $C$. citrinus leaves were collected from the Faculty of Agriculture, Menoufia University. Their extracts were prepared by adding $5 \mathrm{ml}$ of methanol to each $1 \mathrm{gm}$ of dried leaves ground into fine particles; and incubated at room temperature for 72 hours with shaking. This was followed by filtration and concentration by drying in a rotary evaporator. Finally, the crude total extracts yield of the plants were preserved at $4^{\circ} \mathrm{C}$ until use ${ }^{[10]}$.

Preparation of different concentrations from plants extracts: Different weights of both plant extracts were dissolved in one ml dimethylsulfoxide (DMSO) then diluted by dechlorinated water ${ }^{[20]}$. The concentrations obtained for $S$. nigrum were $15 \mathrm{mg} / \mathrm{L}, 20 \mathrm{mg} / \mathrm{L}, 25$ $\mathrm{mg} / \mathrm{L}$ and $50 \mathrm{mg} / \mathrm{L}^{(21)}$, and for $C$. citrinus they were 20 $\mathrm{mg} / \mathrm{L}, 30 \mathrm{mg} / \mathrm{L}, 40 \mathrm{mg} / \mathrm{L}$ and $60 \mathrm{mg} / \mathrm{L}^{[22]}$.

Cercarial shedding from infected snails: Infected $B$. alexandrina snails were purchased from Schistosome Biological Supply Program (SBSP) Unit at Theodor Bilharz Research Institute (TBRI). They were suspended in $100 \mathrm{ml}$ dechlorinated water and left under white fluorescent light for $30 \mathrm{~min}$ to release cercariae ${ }^{[23]}$. The number of cercariae was counted three times and the average number of cercariae per $1 \mathrm{ml}$ was calculated ${ }^{[24]}$.

Cercaricidal activity of plant extracts: An average of 50 cercariae were placed in $5 \mathrm{~cm}$ Petri dishes; then 2 $\mathrm{ml}$ of each prepared concentration of the extracts were added per dish. To the same number of cercariae, $2 \mathrm{ml}$ aged chlorine-free water was added as control. Three replicates were used to detect number of dead cercariae with each concentration to determine the different lethal concentrations ( $\mathrm{LC})$ of both plants $\left(\mathrm{LC}_{10}, \mathrm{LC}_{25}, \mathrm{LC}_{50}\right.$ and $\mathrm{LC}_{90}$ ) after one hour of exposure. Cercariae were considered dead when they stopped movement, sank down and when their tails were detached ${ }^{[25]}$. Motility and morphology of the cercariae through the period of exposure were examined by a stereomicroscope ${ }^{[5]}$.

Assessment of genetic polymorphism in S. mansoni cercariae: The obtained $\mathrm{LC}_{50}$ of both plants (25 $\mathrm{mg} / \mathrm{L}$ for $S$. nigrum, and $40 \mathrm{mg} / \mathrm{L}$ for $C$. citrinus) was used. The cercariae were divided into three groups: group A (control non-exposed cercariae), group B (cercariae exposed to $S$. nigrum at concentration 25 $\mathrm{mg} / \mathrm{L}$ ); and group C (cercariae exposed to C. citrinus at concentration $40 \mathrm{mg} / \mathrm{L}$ ). The exposed cercariae were then collected for DNA extraction and investigated by RAPD-PCR.

Extraction of DNA ${ }^{[26]}$ : DNA extraction was performed using DNeasy Mini Kit (QIAGEN), according to manufacturer's instructions. Briefly, cercarial suspensions were first lysed using proteinase $\mathrm{K}$. Buffering conditions were adjusted to provide optimal DNA binding conditions and the lysate was loaded into the QIA shredder spin column after centrifugation. The supernatant was mixed with buffer then loaded into DNeasy Mini spin column. During centrifugation, DNA was selectively bound to the DNeasy membrane followed by two efficient wash steps, then, DNA was eluted in AE buffer ready for use.

RAPD-PCR Procedure ${ }^{[14]}$ : Different universal random primers (Operon Technologies, Alameda, CA, USA) were screened in RAPD analysis for their ability to match the genome of $S$. mansoni cercariae and produce sufficient amplification products. PCR reactions were conducted using 7 of these primers (Table 1), and DNA amplifications were performed in an automated thermal cycler (model Techno 512).

Table 1. Primers and their nucleotide sequences.

\begin{tabular}{lcc}
\hline \hline No. & Name & \multicolumn{1}{c}{ Sequence } \\
\hline $\mathbf{1}$ & 14A & 5` CTC TCT CTC TCT CTC TTG 3` \\
$\mathbf{2}$ & 44B & 5` CTC TCT CTC TCT CTC TG 3` \\
$\mathbf{3}$ & HB-08 & 5` GAG AGA GAG AGA GG 3` \\
$\mathbf{4}$ & HB-09 & 5` GTG TGT GTG TGT GC 3` \\
$\mathbf{5}$ & HB-11 & 5` GTG TGT GTG TGT TGT CC 3` \\
$\mathbf{6}$ & HB-13 & 5` GAG GAG GAG GC 3` \\
$\mathbf{7}$ & HB-15 & 5` GTG GTG GTG GC 3` \\
\hline \hline
\end{tabular}

The cycler was programmed for $5 \mathrm{~min}$ initial denaturation step at $94^{\circ} \mathrm{C}$, followed by 45 cycles of 1 $\min$ at $57^{\circ} \mathrm{C}$ of primer annealing, and $2 \min$ at $72^{\circ} \mathrm{C}$ of elongation. The reaction was finally stored at $72^{\circ} \mathrm{C}$ for 10 min. The reaction products were resolved by $2 \%$ agarose gel (stained with ethidium bromide) electrophoresis. RAPD gels were processed using Quantity One software (Bio-Rad) which identifies DNA fragments using an optimized set of parameters (as reported in Quantity 
One user guide for version 4.2 Windows Bio-Rad Laboratories) which was manually adjusted by visual inspection. Fragments identification was then used to create a qualitative data matrix of presence (1) or absence (0) that was processed using SPSS software program (version 22). The resulting data was used to construct a dendrogram by means of the UPGMA (unweight pair-group method with arithmetical averages) algorithm ${ }^{[27]}$. The amplification products were fragmented, and the bands produced were classified into polymorphic (partially common between species); monomorphic (common in all species at equal molecular weights (MW)); and positive (unique) marker (species specific). Polymorphism percentage (\%) is used to refer to the percentage of the total number of polymorphic and positive marker bands per the total number of bands ${ }^{[15]}$.

Statistical analysis: Data were analyzed using SPSS version 22 for calculation of the mean number of dead cercariae in the three replicates for each prepared concentration of each extract; then, $\mathrm{LC}_{10}, \mathrm{LC}_{25}, \mathrm{LC}_{50}$ and $\mathrm{LC}_{90}$ were determined. Polymorphism percentage was calculated as: polymorphic fragments $(\mathrm{PF})+$ positive unique bands/Total amplified fragments (TAF).

\section{RESULTS}

Motility of $S$. mansoni cercariae and their morphological changes: Cercariae exposed to both plant extracts were slower, shorter and darker in color with loss of brightness than those in non-exposed (control). They also showed swollen head, abnormal shape, head separation from tail and disintegration (Figure 1).

\section{Cercarial mortality of $S$. mansoni cercariae after one hour of exposure to different $S$. nigrum and $C$. citrinus extracts concentrations with determination of LCs: Cercarial decreased motility and increased mortality occurred with increasing concentration of extracts (Table 2). Dead cercariae were motionless at the bottom of Petri dish and with separated tails. The lethal concentrations for methanol extracts of $S$. nigrum and $C$. citrinus that killed $50 \%\left(\mathrm{LC}_{50}\right)$, of $S$. mansoni cercariae were $25 \mathrm{mg} / \mathrm{L}$. Methanol extract of $S$. nigrum leaves showed higher cercaricidal activity with a toxicity of 1.2 times higher than that of $\mathrm{C}$. citrinus as $\mathrm{LC}_{90}$ values were $50 \mathrm{mg} / \mathrm{L}$ and $60 \mathrm{mg} / \mathrm{L}$ for $S$. nigrum and $C$. citrinus, respectively.}
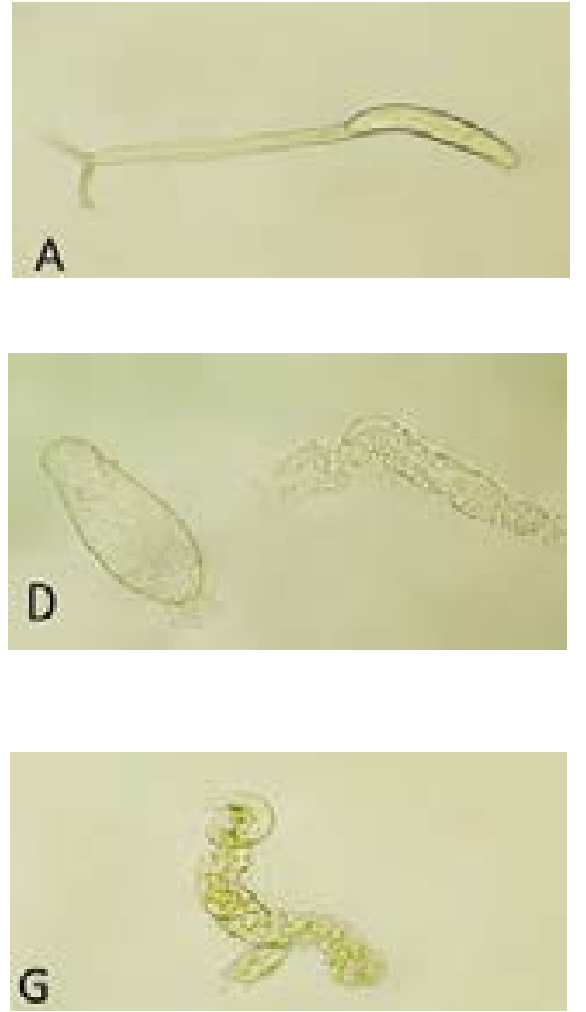
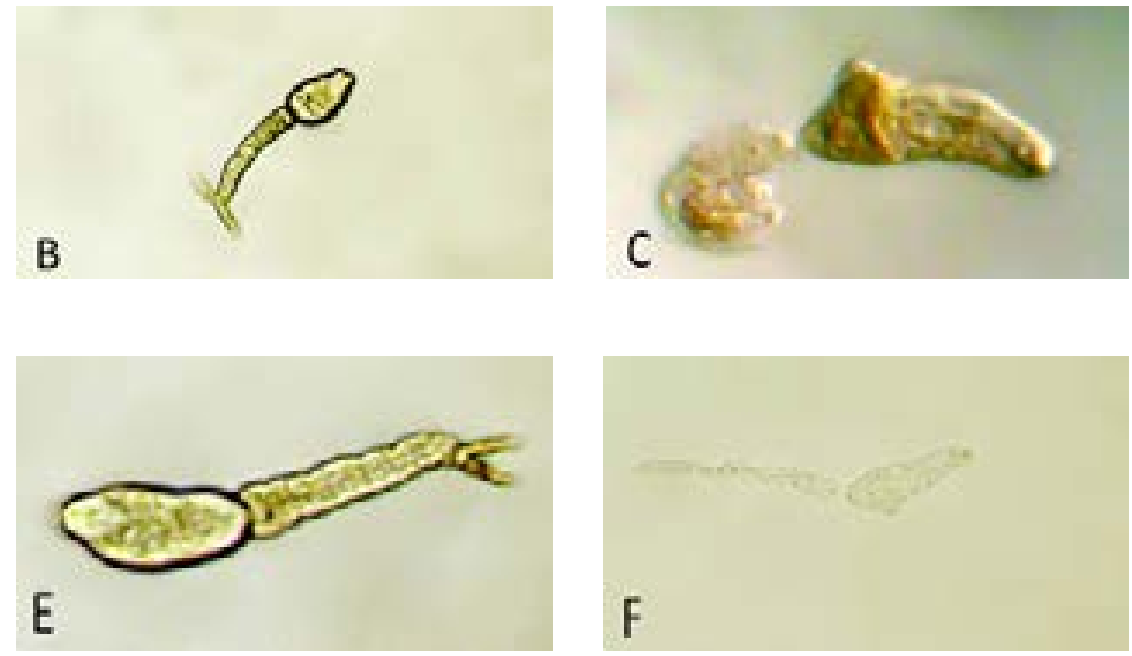

Fig. 1.

A) Non- exposed S. mansoni cercaria (control) shows normal length and shape of the head and tail with bright appearance and smooth surface wall. (B-D) S. mansoni cercariae exposed to $S$. nigrum at different concentrations. B) At $20 \mathrm{mg} / \mathrm{L}$, it shows darkness, swollen head, corrugation of the tail and shortness (x100). C) At $25 \mathrm{mg} / \mathrm{L}$, it shows severe deformity, swollen head with partial separation and twitched tail (x400). D) At $50 \mathrm{mg} / \mathrm{L}$, it shows complete detachment of head and tail with disintegration and loss of contents (x400). (E-G) S. mansoni cercariae exposed to $C$. citrinus at different concentrations. E) At $30 \mathrm{mg} / \mathrm{L}$, it shows swollen and deformed head (x400). F) At $40 \mathrm{mg} / \mathrm{L}$, it shows partial separation of head and tail (x400). G) At $60 \mathrm{mg} / \mathrm{L}$, it shows severe deformity and disintegration (x400).

Table 2. Different lethal concentrations (LC) of S. nigrum and C. citrinus leaves for S. mansoni cercariae.

\begin{tabular}{lcccc}
\hline \hline \multirow{2}{*}{ Plant species } & \multicolumn{4}{c}{ Time of exposure (one hour) } \\
\cline { 2 - 5 } & $\mathbf{L C}_{\mathbf{1 0}} \mathbf{( m g / L )}$ & $\mathbf{L C}_{\mathbf{2 5}} \mathbf{( m g / L )}$ & $\mathbf{L C}_{\mathbf{5 0}}(\mathbf{m g} / \mathbf{L})$ & $\mathbf{L C}_{\mathbf{9 0}}(\mathbf{m g} / \mathbf{L})$ \\
\hline S. nigrum & 15 & 20 & 25 & 50 \\
C. citrinus & 20 & 30 & 40 & 60 \\
\hline \hline
\end{tabular}


RAPD-PCR analysis: The total number of bands resolved in agarose gel for both control and exposed cercariae to plant extracts $\left(\mathrm{LC}_{50}\right)$ was 38 with molecular size ranging from 45 to 321 bp (Figure 2). This shows genetic polymorphism in cercariae exposed to $S$. nigrum and $C$. citrinus. Out of these 38 bands, 12 were monomorphic (shared among all groups) and 26 bands were polymorphic (Table 3). Data in table (4) revealed that cercariae exposed to $S$. nigrum (Group B) revealed a higher number (20) of polymorphic bands, and C. citrinus (Group C) revealed 16 bands which were different from those of control group either by presence or absence.
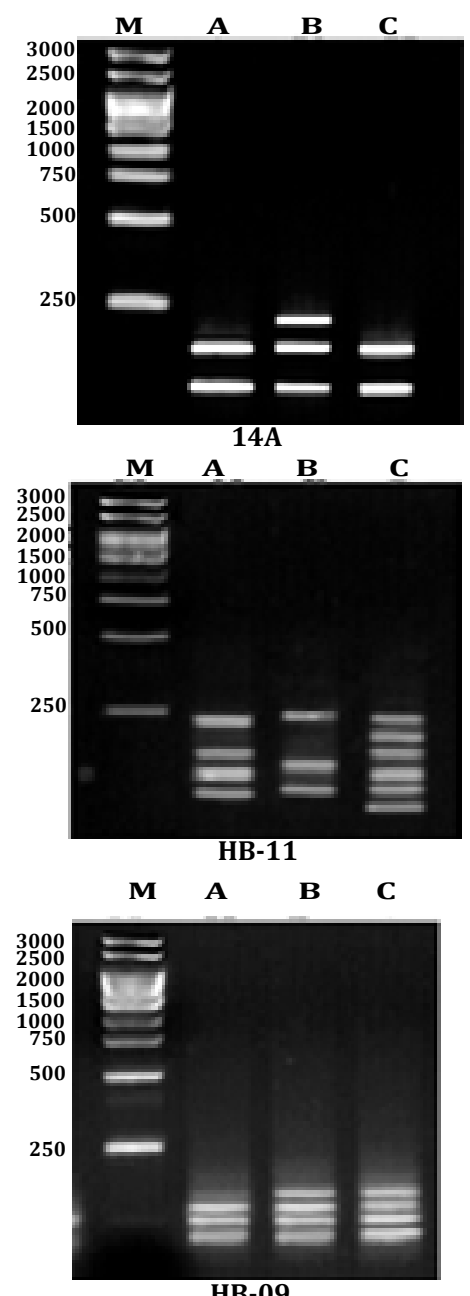

HB-09

Table 3. DNA fragments generated by 7 primers used in RAPD- PCR of control and exposed cercariae and polymorphism percentage.

\begin{tabular}{lcccc}
\hline \hline Primers & TAF & MF & PF and positive unique & Polymorphism (\%) \\
\hline 14A & 3 & 2 & 1 & 33.33 \\
44B & 6 & 0 & 6 & 100.00 \\
HB-08 & 3 & 2 & 1 & 33.33 \\
HB-09 & 4 & 3 & 1 & 25.00 \\
HB-11 & 8 & 1 & 7 & 87.50 \\
HB-13 & 7 & 0 & 7 & 100.00 \\
HB-15 & 7 & 4 & 3 & 42.85 \\
\hline Total & 38 & 12 & 26 & 68.42 \\
\hline
\end{tabular}

TAF: Total amplified fragments, MF: monomorphic fragments, PF: polymorphic fragments and HB-09 primers.
The greatest total number of bands was 8 obtained by primer HB-11 followed by HB-13 and HB-15 (7 bands by each) and 44B primer that generated 6 bands. The lowest number was obtained by $14 \mathrm{~A}$ and HB08 primers ( 3 bands by each) (Figure 2). Regarding the band polymorphism, the highest percentage of polymorphism was obtained with $44 \mathrm{~B}$ and $\mathrm{HB}-13$ primers (100\% polymorphism) followed by HB-11 primer, reaching $87.5 \%$, and the lowest percentages were obtained with HB-09 (25\%) and 14A and HB-08 primers (33.3\%).

Fig. 2. RAPD-PCR patterns generated from DNA of control non-exposed cercariae (group A) and exposed cercariae (groups B and C) using 14A, HB-13, 44B, HB-11, HB-15, HB-08

Lane M: DNA Ladder 100 bp; Lane A: control; Lane B: group B; Lane C: group C.

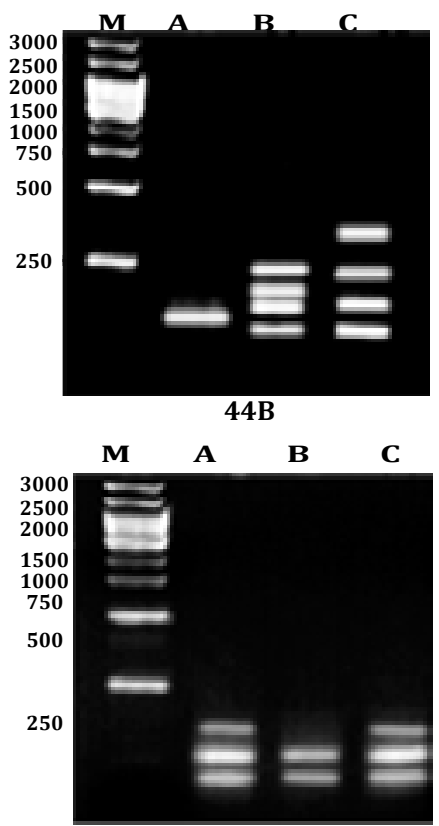

HB-08
Table 4. Number of bands that either appeared with exposed cercariae in each group and were absent in control cercariae or vice versa.

\begin{tabular}{lcc}
\hline \hline Primers & S. nigrum (Group B) & C. citrinus (Group C) \\
\hline 14A & 1 & 0 \\
44B & 5 & 5 \\
HB-08 & 1 & 0 \\
HB-09 & 1 & 1 \\
HB-11 & 5 & 2 \\
HB-13 & 5 & 6 \\
HB-15 & 2 & 2 \\
\hline Total & 20 & 16 \\
\hline \hline
\end{tabular}


The dendrogram illustrated the genetic relationship between exposed cercariae groups (B and C) and nonexposed control cercariae (group A) (Figure 3). It separated them into two major clusters; I and II. Cluster I included control cercariae (group A), while cluster
II included exposed groups: group B (cercariae preexposed to $\mathrm{LC}_{50}$ of $S$. nigrum) and group $\mathrm{C}$ (cercariae pre-exposed to $\mathrm{LC}_{50}$ of $C$. citrinus). This separation revealed genetic difference between control and exposed cercariae.

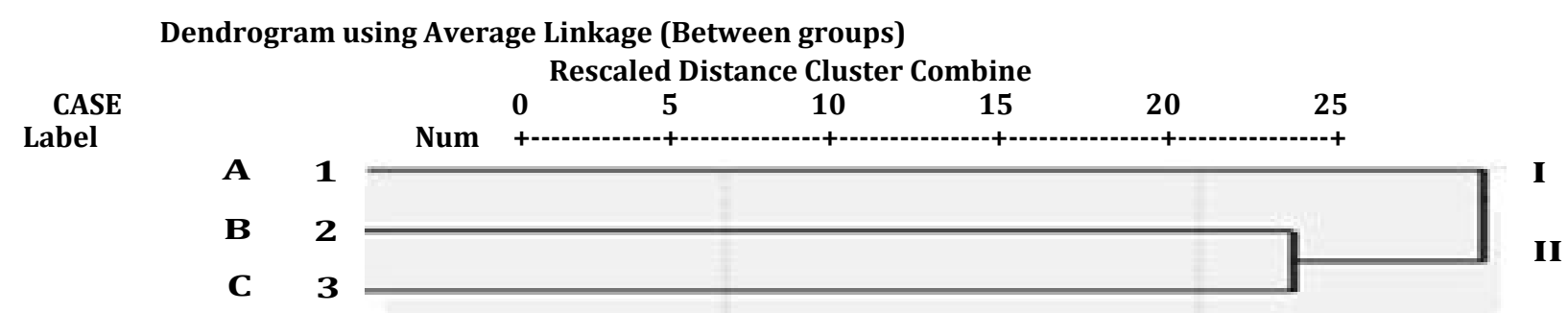

Fig. 3. Dendrogram illustrating the genetic difference between exposed cercariae (groups $B$ and $C$ ) in comparison with nonexposed cercariae (group A) based on RAPD data.

\section{DISCUSSION}

Interruption of schistosomes life cycle by any tool targeting their larval forms will contribute significantly in controlling schistosomiasis. Schistosomes have a complex life cycle involving freshwater intermediate host snails. In this study we endeavored to determine the potential of methanol extracts from $S$. nigrum and $C$. citrinus leaves in controlling schistosomiasis through their cercaricidal effects. To our knowledge, this is the first study for the use of $C$. citrinus as a cercaricidal agent. Exposure of $S$. mansoni cercariae for one hour to different concentrations of methanol extract of $S$. nigrum leaves revealed that $\mathrm{LC}_{50}$ and $\mathrm{LC}_{90}$ values were 25 and $50 \mathrm{mg} / \mathrm{L}$, respectively. These results parallel those of Ahmed and Ramzy ${ }^{[11]}$ who recorded the cercaricidal properties of water extract of $S$. nigrum leaves against $S$. haematobium and S. mansoni cercariae. Hammami et al., ${ }^{[28]}$ attributed its cercaricidal activity to the presence of flavonoids, terpenoids, and saponosides. Bagalwa et al., ${ }^{[29]}$ reported high cercaricidal activity of mixed Solamargine and $\beta$-Solamarine solution against free swimming cercariae and concluded that cercariae were killed or so attenuated to cause infection or become mature and cause significant pathology. Also, Al-Daihan ${ }^{[30]}$ recorded that sub-lethal concentration of $S$. nigrum $\left(\mathrm{LC}_{25}\right)$ was potent in inhibiting and disturbing the biochemical profile of the snail hosts affecting host-parasite relationship. El-Sherbini et al., ${ }^{[10]}$ reported the molluscicidal properties of extracts of different Solanum species leaves and confirmed that environmentally they are safe agents for control of human schistosomiasis; and hence they are the most suitable molluscicides for biological application due to their very low toxicity to fish.

Our recorded lethal concentrations of methanol extract of $C$. citrinus, were $40 \mathrm{mg} / \mathrm{L}_{\left(\mathrm{LC}_{50}\right)}$ and 60 $\mathrm{mg} / \mathrm{L}\left(\mathrm{LC}_{90}\right)$, coinciding with results of Ali et al., ${ }^{[22]}$ who recorded the lethal value for methanol extract of $C$. citrinus on brine shrimp larvae. C. citrinus extracts contain saponins, alkaloids and flavonoids which were proved as molluscicidal agents in different countries ${ }^{[31]}$. Due to their froth-forming ability, saponins affect the surface tension and are thus lethal to snail vectors and cercariae of schistosomes. Saponins also possess hemolytic action by forming complexes with cholesterol in red blood cell membranes causing their collapse and release of hemoglobin ${ }^{[6]}$. Formerly, the methanol plant extract of $C$. viminalis was tested to evaluate the anti-schistosomal activity and the results revealed high effect since the $\mathrm{LC}_{50}(\leq 15 \mu \mathrm{g} /$ $\mathrm{ml}$ ) was very low ${ }^{[32]}$ which agrees with our results regarding C. citrinus.

The present data shows that the methanol extract of $S$. nigrum leaves was 1.2 times more toxic to the cercariae of $S$. mansoni $\left(\mathrm{LC}_{90}\right.$ values of $50 \mathrm{mg} / \mathrm{L}$ ) than those of $C$. citrinus $\left(\mathrm{LC}_{90}\right.$ values of $60 \mathrm{mg} / \mathrm{L}$ ), which is the plant extract used for the first time as a cercaricidal agent in the present study. Our results showed that the two plants used were effective cercaricidals, even with sub-lethal doses. In support of these findings are the parasitological, histopathological, and scanning electron microscopical parameters that we previously studied in mice infected with cercariae exposed to $\mathrm{LC}_{50}$ of $S$. nigrum and $C$. citrinus methanol extracts ${ }^{[33]}$. Also, Ahmed and Rifaat $^{[21]}$ reported that crude water extract of $S$. nigrum leaves attenuated $S$. mansoni cercariae and significantly reduced their ability to penetrate mice skin. In addition El-Ansary et al., ${ }^{[34]}$ showed that the pathogenicity in mice achieved by infection with attenuated cercariae released from snails treated by $\mathrm{LC}_{10}$ of $S$. nigrum dry powdered leaves, was remarkably lower than in those infected with normal cercariae. Likewise, El-Refai et al., ${ }^{[35]}$ supported the in vivo activity of aqueous extract of $C$. citrinus as alternative chemotherapy against both prepatent and patent phases of $S$. mansoni in infected mice. 
Initially, microscopic examination of cercariae exposed for $1 \mathrm{~h}$ to plant extracts showed progressive decrease in motility until motionless with increase of extract concentration used. Morphological changes noted were shortened length, abnormal shape, abnormal motility, head separation from tail, and sometimes disintegration. Similar findings were obtained after red cedar wood oil exposure to the water surface for a few minutes as cercariae altered their behavior by vigorously swimming to the bottom followed by immobilization or occasional tail twitching ${ }^{[5]}$.

Various natural compounds have been shown to be toxic to cercariae. Also, some of them were reported to possess components that can inhibit the penetration of cercariae through human $\operatorname{skin}^{[36]}$ such as crude aqueous extract of Zingiber officinale ${ }^{[37]}$, pure compounds as artemether ${ }^{[38]}$ and the latex of Euphorbia conspicua ${ }^{[39]}$. dos Santos et al., ${ }^{[9]}$ reported a potent cercaricidal activity of the ethanol extract of the rhizome of Jatropha elliptica.

RAPD-PCR was used in the present study, to investigate the genetic changes of cercariae exposed to $\mathrm{LC}_{50}$ of methanol extract from $S$. nigrum and $C$. citrinus leaves in comparison with control non-exposed cercariae. The applied seven primers successfully amplified products from genomic DNA from pooled cercariae of each group. Also, they presented different band polymorphism patterns with monomorphic bands of similar molecular weights. RAPD-PCR was found to be a rapid and low-cost technique for identification of polymorphic bands representing DNA amplification extracted from different stages of the $S$. mansoni development cycle exposed to different periods of in vivo treatments ${ }^{[40]}$.

In our study, cercariae used were genetically from the same infected $B$. alexandrina snails. Cercariae exposed to $S$. nigrum revealed a higher number of band polymorphism (20 bands,) than that obtained by cercariae exposed to $C$. citrinus (16 bands) which were also different from those of control group either by presence or absence. These results showed that each group gave a different pattern with the same primer, although some fragments could be detected as common. The extent to which RAPD-PCR fragments were shared among different groups reflects the genetic variability between cercariae exposed groups and control group. According to Clark and Lanigan ${ }^{[41]}$, genetic polymorphism may be caused by mutation, deletion or replacement of a single base at specific loci resulting in change in the nucleotide sequence that could be detected by appearance of amplified fragments with different DNA sequence.

The dendrogram reflected genetic difference between control and exposed cercariae due to DNA changes of mutation, deletion or damage in exposed cercariae. This agrees with Williams et al., ${ }^{[14]}$ who recommended RAPD-PCR as a simple, sensitive and effective method for detection of genetic damages that change the primer binding sites altering the electrophoretic band profile. Also, Riad et al., ${ }^{[42]}$ recorded that RAPD-PCR pattern of DNA of schistosomes recovered from garlic-treated groups showed $65 \%$ to $68 \%$ similarity percentages with those of control ones.

The RAPD technique has long been asserted for studying the genetic diversities among molluscan species $^{[43]}$ and the heterogeneity of schistosomal strains ${ }^{[44]}$. That is besides, the use of RAPD-PCR to genetically differentiate resistant from susceptible B. glabrata snails to $S$. mansoni miracidia ${ }^{[45,46]}$. Also, Oliveira et al., ${ }^{[47]}$ recorded data indicating great genetic variability among susceptible and resistant strains of B. glabrata and B. tenagophila by RAPD-PCR. However, this technique has not been explored in the fields of drug development to assess genetic damage ${ }^{[48]}$ and no references could be cited for the effect of any drug on the genomic DNA profiles of schistosomal cercariae.

In conclusion, $S$. nigrum and $C$. citrinus are effective cercaricidal agents. This study provides alternative cheap, safe and effective control agent against schistosomiasis especially in endemic countries. Moreover, RAPD-PCR is useful for examining the genetic polymorphism of schistosomal cercariae that could result from any treatment, and it can be used in assessment of genetic damage in the fields of drug development. Finally, cercarial sublethal concentrations of plant molluscicides applied on water surface could be of great value to minimize water transmission of schistosomiasis. In addition, they could be recommended for clinical application as topics or skin repellents to prevent skin penetration or even for attenuation of cercarial infectivity to the final host. This is a new tool in schistosomiasis control in endemic areas where restricting people from coming in close contact with infective water is an impracticable task.

Author contribution: GS Sadek and NM Harba designed the study protocol. NM Harba contributed with MF Faheem in performing the laboratory studies. The manuscript was written by NM Harba and reviewed by GS Sadek.

\section{Conflict of interest: None.}

\section{REFERENCES}

1. World Health Organization. Schistosomiasis: progress report 2001-2011 and strategic plan 2012-2020. Geneva, Switzerland: WHO, 2013.

2. Obare B, Yole D, Nonoh J, Lwande W. Evaluation of cercaricidal and miracicidal activity of selected plant extracts against larval stages of Schistosoma mansoni. JNSR 2016; 6 (22): 24-31. 
3. Pereira AS, Cavalcanti NL, Nascimento GA, Nascimento-Silva JL, Padilha RJ, Viegas LF, et al. Morphological and morphometric study of cercariae and adult worms of Schistosoma mansoni (SLM strain) isolated from infected mice. Parasitol Res 2013; 112:1087-1096.

4. Hassan AA, Mahmoud AE, Hassan RA, Huseein EM: Evaluation of Euphorbia aphylla, Ziziphus spina-Christi and Enterolobium Contortisiliquum as molluscicidal agents. J Am Sci 2011; 7: 511-520.

5. Naples JM, Shiff C, Halden R. Reduction of infectivity of schistosome cercariae by application of cercaricidal oil to water. Am J Trop Med Hyg 2005; 73(5): 956-961.

6. Adewumi AAJ, Aina VO, Zhang CS, He Z. Assessment of the molluscicidal activities of Sasanqua saponin. CRJBS 2013: 5(1), 1-4.

7. Dai JR, Li YZ, Wang WE, Xing YT, Qu GL, Liang YS. Resistance to niclosamide in Oncomelania hupensis, the intermediate host of Schistosoma japonicum: should we be worried? First View 2014; 1 -9.

8. Duval D, Galinier R, Mouahid G, Toulza E, Allienne JF, Portela J, et al. A novel bacterial pathogen of Biomphalaria glabrata: a potential weapon for schistosomiasis control?. PLoS Negl Trop Dis 2015; 9(6): e0003815.

9. dos Santos AF, Fonseca SA, César FA, Albuquerque MC, Santana JV, Santana AE. A penta-substituted pyridine alkaloid from the rhizome of Jatropha elliptica (Pohl) Muell. Arg. is active against Schistosoma mansoni and Biomphalaria glabrata. Parasitol Res 2014; 113(3):1077-1084.

10. El-Sherbini GT, Zayed RA, and El-Sherbini ET. Molluscicidal activity of some Solanum species extracts against the snail Biomphalaria alexandrina. Parasitol Res 2009;1- 5.

11. Ahmed AH, Ramzy RM. Laboratory assessment of the molluscicidal and cercaricidal activities of the Egyptian weed, Solanum nigrum leaves. Ann Trop Med Parasitol 1997; 91(8):931-937.

12. Burchett M, Mousine R, Tarran J. Phytomonitoring for urban environmental management. Air Pollut Plant Biotechnol 2002; pp. 61-91.

13. Gohar AA, Maatooq GT, Gadara SR, Abo El-maaty WS, El-Shazly AM. Molluscicidal activity of the methanol extract of Callistemon viminalis (Sol. ex Gaertner) G.Don ex Loudon fruits, bark and leaves against Biomphalaria alexandrina snails. Iran J Pharm Res 2014; 13:505-514.

14. Williams J, Kubelik AR, Livak KJ. DNA polymorphisms amplified by arbitrary primers are useful as genetic markers. Nucleic Acid Res 1990; 18: 6531-6535.

15. Khalil AI, Morsy GH, Lashein GH, Abd El-Mottaleb DI, Sharaf AA. Molecular variations based on RAPD among Oxyurids in Egypt. PUJ 2013; 6(1):39-50.

16. Barral V, This $P$, Imbert-Establet $D$, Combes $C$, Delseny M. Genetic variability and evolution of the Schistosoma genome analyzed by using random amplified polymorphic DNA markers. Mol. Biochem. Parasitol 1993; 59(2):211-222.

17. de Oliveiraa RN, Ferreirab PM, Calado M, Belo $S$, Afonso A, Garciae VL, et al. Sesquiterpenes effects on DNA of Schistosoma mansoni after in vivo treatment. Gene Reports 2018;11: 205-212.

18. Rizk MZ, Khalil WK, Abdel-Hamid AZ, Haggag SH, Hamed MA, Ahmed MB et al. Molecular approach for detection compatibility/incompatibility of Egyptian Biomphalaria alexandrina and Bulinus truncatus snails with their miracidia. Inter Pharm Clin Res J 2013; 5(3): 96-104.

19. Kumar NS, Gurusubramanian G. Random amplified polymorphic DNA (RAPD) markers and its applications. Sci Vis 2011; 11 (3):116-124.

20. Adenusi AA, Odaibo AB. Effects of vary in concentrations of the crude aqueous and ethanolic extracts of dalbergia sissoo plant parts on Biomphalaria pfeifferi egg masses. Afr Trad J 2009; 6: 139-149.

21. Ahmed AH, Rifaat M. Effects of Solanum nigrum leaves water extract on the penetration and infectivity of Schistosoma cercariae. J Egypt Soc Parasitol. 2005; 35(1): 33-40.

22. Ali N, Ahmed G, Shah SW, Shah I, Ghias M, Khan I. Acute toxicity, brine shrimp cytotoxicity and relaxant activity of fruits of Callistemon citrinus curtis. BMC Complement Altern Med 2011; 11(99):1-8.

23. Liang YS, Bruce JI, Boyd DA. Laboratory cultivation of schistosome vector snails and maintenance of schistosome life cycles. Proc, $1^{\text {st }}$ Sino-American Symp 1987; 1: 34-48.

24. Moore DL, Grove DL, Warren KS. The S. mansoni egg granuloma. J Pathol 1977; 121: 41-50.

25. Eissa MM, El Bardicy S, Tadros M. Bioactivity of miltefosine against aquatic stages of Schistosoma mansoni, Schistosoma haematobium and their snail hosts, supported by scanning electron microscopy. Parasit Vectors 2011; 4:73.

26. Knebelsberger T, Stöger I. DNA extraction, preservation, and amplification. In: DNA Barcodes: Methods and Protocols, Methods in Molecular Biology (Eds. Kress WJ, Erickson DL), 2012; 311-338. Springer Science+Business Media, LLC, New York.

27. Sensi E, Vignani R, Scali M, Masi E, Cresti M. DNA fingerprinting and genetic relatedness among cultivated varieties of Olea europaea $L$. estimated by AFLP analysis. Scientia Horticulturae 2003;97: 379-388.

28. Hammami H, Ayadi A, Damak M, Mezghani-Jarraya R. Molluscicidal activity of various solvent extracts from Solanum nigrum var. villosum aerial parts against Galba truncatula. Parasite 2011; 18(1): 63-70.

29. Bagalwa M, Nazabadioko L, Sayagh C, Bashwira S, Baluku B. Evaluation of Schistosoma mansoni cercaricidal activity of Solamargine a steroid glycoalkaloid from Solanum syzybrilifolium. Int J Eng Rese Gen Scie 2014; 1(2): 15-23. 
30. Al-Daihan S. Effect of plant molluscicides on selected enzymes related to energy metabolism in Biomphalaria arabica snails molluscan hosts to Schistosoma mansoni in Saudi Arabia. J Egypt Soc Parasitol. 2010; 40(1):187-95.

31. Kiros G, Erko B, Giday M, Mekonnen Y. Laboratory assessment of molluscicidal and cercaricidal effects of Glinus lotoides fruits. BMC Res 2014; 7:220.

32. Yousif F, Wassel G, Boulos L, Labib T, Mahmoud $\mathrm{K}$, El-Hallouty $\mathrm{S}$, et al. Contribution to in vitro screening of Egyptian plants for schistosomicidal activity. Pharm Biol. 2012; 50(6):732-739.

33. Abd El Ghaffar MM, Sadek GS, Harba NM, Faheem MF. Evaluation of the effect of some plant molluscicides on the infectivity of Schistosoma mansoni cercariae. MMJ 2018; 31(4):1-8.

34. El-Ansary A, Mohamed AM, Mahmoud SS, ElBardicy S. On the pathogenicity of attenuated Schistosoma mansoni cercariae released from metabolically disturbed Biomphalaria alexandrina. J Egypt Soc Parasitol 2003:33(3):777-794.

35. El-Refai SA, Atia AF, Mahmoud SF. Effects of Callistemon citrinus aqueous extract on prepatent and patent infections with Schistosoma mansoni in experimentally infected mice. J Helminthol 2018; 2:1-10.

36. De-Carvalho RR, Maldonado AJ, Oliveira-Filho EC, Ribeiro A C, Paumgartten FJ, Rey L. Effects of Euphorbia milli latex on Schistosoma mansoni eggs, miracidia and cercariae. Mem Inst Oswaldo Cruz 1998; 93:235-237.

37. Mostafa OMS, Eid RA, Adly MA. Anti-schistosomal activity of ginger (Zingiber officinale) against Schistosoma mansoni harbored in C57 mice. Parasitol Res 2011;109: 395-403.

38. Abdul-Ghani R, Loutfy N, Sheta M, Hassan A. Artemether shows promising female schistosomicidal and ovicidal effects on the Egyptian strain of Schistosoma mansoni after maturity of infection. Parasitol Res 2011; 108:1199-1205.

39. dos Santos AF, de Azevedo DP, dos Santos RC, de Mendonça DL, Goulart AE. The lethality of Euphorbia conspicua to adults of Biomphalaria glabrata, cercaria of Schistosoma mansoni and larvae of Artemia salina. Bioresour Technol 2007; 98(1): 135-139.

40. Tsai MH, Marx KA, Ismail MM, Tao LF. Randomly amplified polymorphic DNA (RAPD) polymerase chain reaction assay for identification of Schistosoma mansoni strains sensitive or tolerant to anti-schistosomal. J Parasitol 2000;86:146-149.

41. Clark AG, Lanigan MS. Prospects for estimating divergence with RAPDs. Mol Biol Evol 1993;10(5):1096-1111.

42. Riad NHA, Taha HA, Mahmoud YI. Effects of garlic on Schistosoma mansoni harbored in albino mice: molecular characterization of the host and parasite. Gene 2013; 518: 287-291.

43. Langand J, Théron A, Pointier JP, Delay B, Jourdane J. Population structure of Biomphalaria glabrata, intermediate snail host of Schistosoma mansoni in Guadeloupe Island using RAPD markers. J Moll Stud 1999; 65: 425-433.

44. Gasser RB, Bao-Zhen Q Nansen P, Johansen MV, Bøgh $\mathrm{H}$. Use of RAPD for the detection of genetic variation in the human blood fluke, Schistosoma japonicum, from mainland China. Mol Cell Probes 1996; 10: 353-358.

45. Knight M, Miller NA, Patterson CN, Rowe CG, Michaels G, Carr D, et al. The identification of markers segregating with resistance to Schistosoma mansoni infection in the snail Biomphalaria glabrata. Proc Nat Acad Sci USA.1999; 96: 15101515.

46. Lewis FA, Patterson CN, Grzywacz C. Parasite susceptibility phenotypes of F (1) Biomphalaria glabrata progeny derived from interbreeding Schistosoma mansoni resistant and susceptible snails. Parasitol Res 2003; 89: 98-101.

47. Oliveira AL, Da Silva D, Zanotti-Magalhaes EM, Abdel-Hamid AZ, Ribeiro-Paes JT. Schistosome/ mollusk: genetic compatibility. Genet Mol Res 2008; 7: 518-526.

48. Atienzar FA, Jha AN. The random amplified polymorphic DNA (RAPD) assay and related techniques applied to genotoxicity and carcinogenesis studies: a critical review. Mutat Res 2006; 613(2-3), 76-102. 